\title{
Economic Features of the Internet and Network Neutrality
}

\author{
By Nicholas Economides*
}

April 2015

\begin{abstract}
$\underline{\text { Abstract }}$
We discuss the issue of a possible abolition of network neutrality and the introduction of paid prioritization by residential broadband access networks. We show that, in short run analysis where bandwidth is fixed, and in the absence of congestion, network neutrality tends to maximize total surplus. When an ISP violates network neutrality and invests the extra profits to bandwidth expansion, the presence of more bandwidth alleviates the allocative distortion, and can even reverse it. We also discuss the network neutrality issue under the assumption of congestion, and characterize the set of utility functions for which network neutrality is optimal, as well as utility functions where it is optimal to prioritize. Finally, we review regulatory rules in the United States on network neutrality.
\end{abstract}

Keywords: Internet, pricing, network neutrality, price discrimination, prioritization

JEL codes: D43, L11, L13

* Professor of economics, Stern School of Business, New York University, www.stern.nyu.edu/networks/, email: economides@stern.nyu.edu , and Executive Director, NET Institute, www.NETinst.org • 


\section{Economic Features of the Internet and Network Neutrality}

\section{Introduction and Organization}

This chapter focuses on the issue of network neutrality on the Internet. Network neutrality means that content and applications of various types and from various providers are delivered to Internet users without prioritization for which the originators of the content and applications pay the Internet Service Providers (ISPs). Although the Internet developed under network neutrality, after 2005, practically all fixed-line ISPs to residential customers in the USA have demanded that they be paid to prioritize certain flows of Internet traffic. This issue is complex because the large collection of content and applications the Internet carries show significant variation in the desirability of consumers for immediacy in their delivery. It is also complex because the ISPs already get paid from the users, and if they receive payment from the originators of the traffic the resulting two-sided interaction has to be modelled.

We proceed as follows. Section 1 discusses the general structure of the Internet. Section 2 discusses the structure of the Internet. Section 3 discusses the issues that arise because of the potential abolition of network neutrality. Section 4 discusses the regulatory responses in the United States to the issue of network neutrality. Section 5 offer concluding remarks.

\section{General Structure of the Internet}

The Internet is a global network of interconnected networks that connect computing devices. The Internet allows data transfers as well as the provision of a variety of interactive real-time and time-delayed telecommunications services. Internet communication is based on 
common and public protocols. ${ }^{1}$ Close to a billion computing devices are presently connected to the Internet. Figure 1 shows the expansion of the number of nodes connected to the Internet.

\section{Internet Domain Survey Host Count}

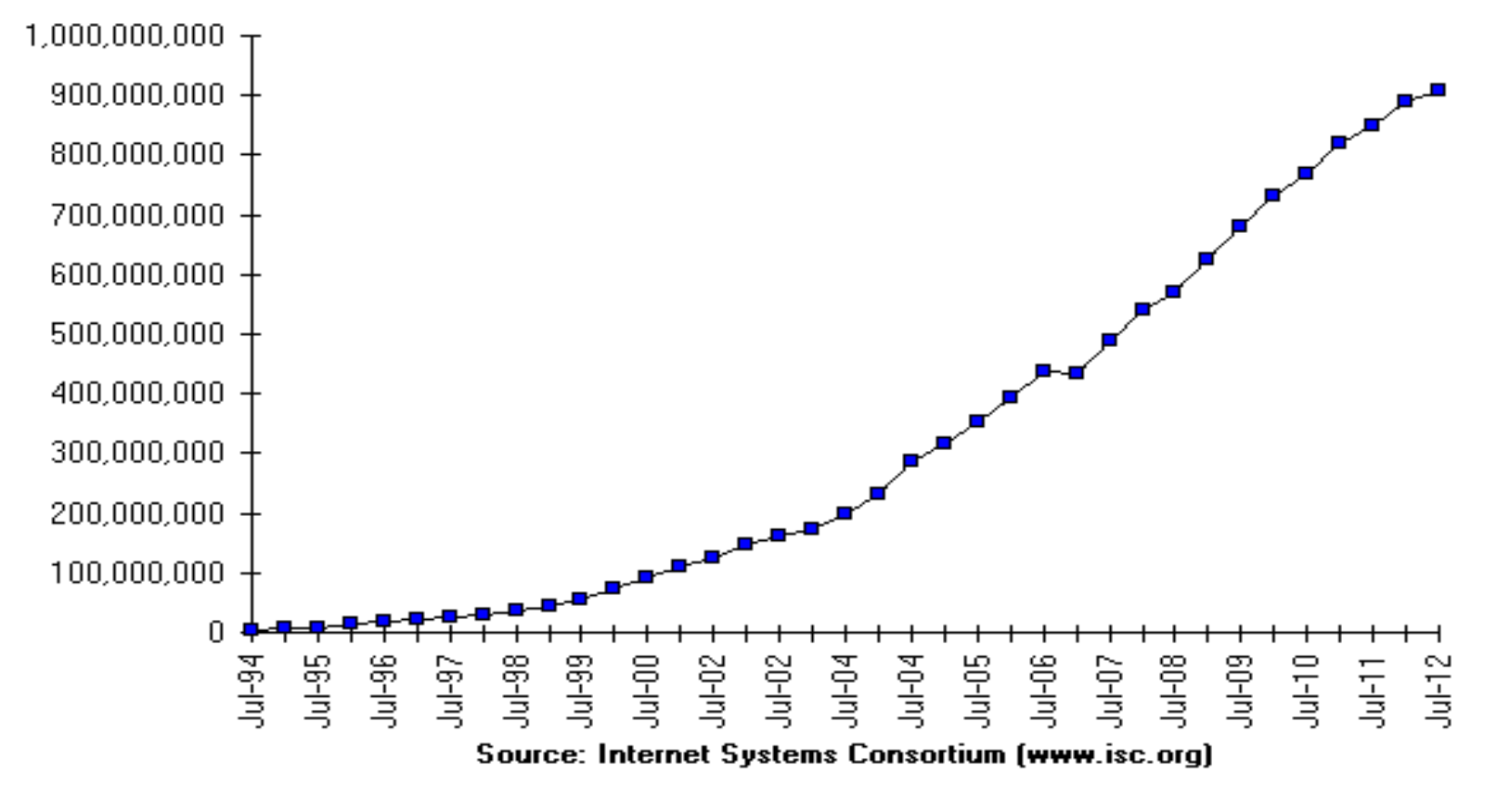

Figure 1

The vast majority of computing devices owned by individuals or businesses connect to the Internet through commercial Internet Service Providers (“ISPs”). Educational institutions and government departments also connect to the Internet but typically do not offer commercial ISP services. Users typically connect to the Internet through cable modems, residential DSL, corporate networks, and, in rare cases, through satellite connection or dialup. Typically, routers and switches owned by ISPs send the caller's packets to a local Point of Presence "POP” of the Internet. Cable modems, and DSL access POPs as well as corporate networks dedicated access circuits connect to high speed hubs. High speed circuits, leased from or owned by telephone companies, connect the high speed hubs forming an "Internet Backbone Network.”

\footnotetext{
${ }^{1}$ See Bradner (1999)
} 
The Internet is based on three basic separate levels/layers of functions of the network:

(i) the hardware/electronics level of the physical network;

(ii) the (logical) network level where basic communication and interoperability is established; and

(iii) the applications/ services level.

Thus, the Internet separates the network interoperability level from the applications/services level. Unlike earlier centralized digital electronic communications networks, such as CompuServe, AT\&T Mail, Prodigy, and early AOL, the Internet allows a large variety of applications and services to ran "at the edge" of the network and not centrally.

Users pay ISPs for access to the whole Internet. Similarly, ISPs pay Internet backbones per month for a pipe of a certain bandwidth for access to the whole Internet. When digital content from provider A, for example, is downloaded by consumer B, both sides, that is, both A and B pay their respective ISPs. Consumer B pays to his ISP through his monthly subscription, and provider A pays similarly. In turn, ISPs pay to their respective backbones through their subscription.

\section{Residential Broadband Access Networks and Network Neutrality}

The present regime on the Internet does not distinguish in terms of price (or in any other way) between information packets depending on the services that these packets provide or depending on who is the sender. This regime, called "network neutrality" or "net neutrality," has prevailed on the Internet since its inception. Presently, information packets from a variety of services and providers are treated equally without discrimination or prioritization by the terminating ISP. 
In 2005, taking advantage of a change in regulatory rules by the Federal Communications Commission that reclassified the Internet as an "information service" rather than a "telecommunications service" and therefore not be subject to non-discrimination provisions, ${ }^{2}$ AT\&T, Verizon and Cable TV networks advocate the introduction of price discrimination based on the originating provider of information packets. ${ }^{3}$ Under the FCC classification, generally discrimination is prohibited in telecommunications services, but allowed in information services. The local residential broadband access networks would like to abolish the regime of net neutrality and substitute for it a complex pricing schedule where the Internet local access network levies charges to the originating party (such as Google or Netflix) even when the originating party is not directly connected to and does not presently have a contractual relationship to the local access network. Notice local access networks propose to impose these charges to providers "on the other side" of the Internet, and not on their ISPs. These providers would keep paying for transport of their information packets to their ISPs.

Figure 1 shows the basic elements of the problem. At the center of the figure, the Internet Backbone is considered effectively competitive. ${ }^{4}$ On the right lower corner is a residential ISP,

\footnotetext{
${ }^{2}$ See Nat'l Cable \& Telecomm. Assn. v. Brand X Internet Services, 125 S. Ct. 2688 (2005).

${ }^{3}$ The issue arose first at an interview of Ed Whitacre, CEO of SBC with BusinessWeek November 7, 2005.

“Q. How concerned are you about Internet upstarts like Google, MSN, Vonage, and others?
}

A. How do you think they're going to get to customers? Through a broadband pipe. Cable companies have them. We have them. Now what they would like to do is use my pipes free, but I ain't going to let them do that because we have spent this capital and we have to have a return on it. So there's going to have to be some mechanism for these people who use these pipes to pay for the portion they're using. Why should they be allowed to use my pipes? The Internet can't be free in that sense, because we and the cable companies have made an investment and for a Google or Yahoo! or Vonage or anybody to expect to use these pipes [for] free is nuts!”

${ }^{4}$ The Internet backbone market is considered effectively competitive. Although public information on this market is limited, during the preceding of the merger of AT\&T with SBC and MCI with Verizon, these companies had to disclose their traffic to the Department of Justice, which is shown in the table below. We see that concentration is significant but not extreme. There are two additional reasons that increase competition on the Internet backbone. First, the (long distance) connection from point A to point B (points of presence) is a homogeneous good. Second, there is a tremendous amount of "dark fiber" which has been laid in the ground and only requires the addition of electronics to be functional. Thus, homogeneity of the good and overcapacity drive down prices on the Internet backbone. 
such as AT\&T. Residential ISPs collect a subscription price $\square$ from residential customers. At the top left corner, there are content and applications providers, such as Google, Disney and Netflix. They may receive a payment $p$ from residential customers, while some content and information are provided for free and supported by advertising. AT\&T and other residential ISPs propose to collect fees $s 1, \ldots$, sn from content and applications providers. In return, residential ISPs propose to offer different degrees of prioritization to content and applications providers. At present, in the regime of network neutrality, all prices $s 1, \ldots . ., s n$ are zero and there is no paid prioritization.

\begin{tabular}{|c|c|c|c|c|c|}
\hline Company & \multicolumn{4}{|l|}{ Traffic } & $\begin{array}{l}\text { Market Share Among } \\
\text { Providers }\end{array}$ \\
\hline & 1Q2004 & 2Q2004 & 3Q2004 & 4Q2004 & 4Q2004 \\
\hline A (AT\&T) & 37.19 & 38.66 & 44.54 & 52.33 & $12.58 \%$ \\
\hline B & 36.48 & 36.50 & 41.41 & 51.31 & $12.33 \%$ \\
\hline $\mathbf{C}$ & 34.11 & 35.60 & 36.75 & 45.89 & $11.03 \%$ \\
\hline MCI & 24.71 & 25.81 & 26.86 & 30.87 & $7.42 \%$ \\
\hline $\mathbf{E}$ & 18.04 & 18.89 & 21.08 & 25.46 & $6.12 \%$ \\
\hline $\mathbf{F}$ & 16.33 & 17.78 & 17.47 & 19.33 & $4.65 \%$ \\
\hline G & 16.67 & 15.04 & 14.93 & 15.19 & $3.65 \%$ \\
\hline $\begin{array}{l}\text { Total traffic } \\
\text { top } 7 \text { networks }\end{array}$ & 183.53 & 188.28 & 203.04 & 240.38 & $57.78 \%$ \\
\hline Total traffic all networks & 313 & 313 & 353 & 416 & \\
\hline
\end{tabular}


Figure 1: Schematic topology of the Internet showing possible violations of network neutrality

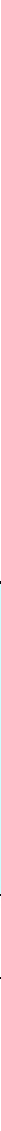


The imposition of price discrimination on the provider side of the market and not on the subscriber is a version of two-sided pricing. This is uniquely possible for firms operating in a network structure. ${ }^{5}$ Figure 2 shows the setup of Figure 1 in an abstraction that may also be useful in analyzing other industries. The ISP is a platform that is paid $\mathrm{C}$ by consumers on one side of the market and $s$ by content and applications providers on the other side of the market. Consumers may also pay a price $p$ directly to content or applications providers. This analysis is based on the framework of Armstrong (2006).

Figure 2: A residential ISP as a platform in a two-sided market

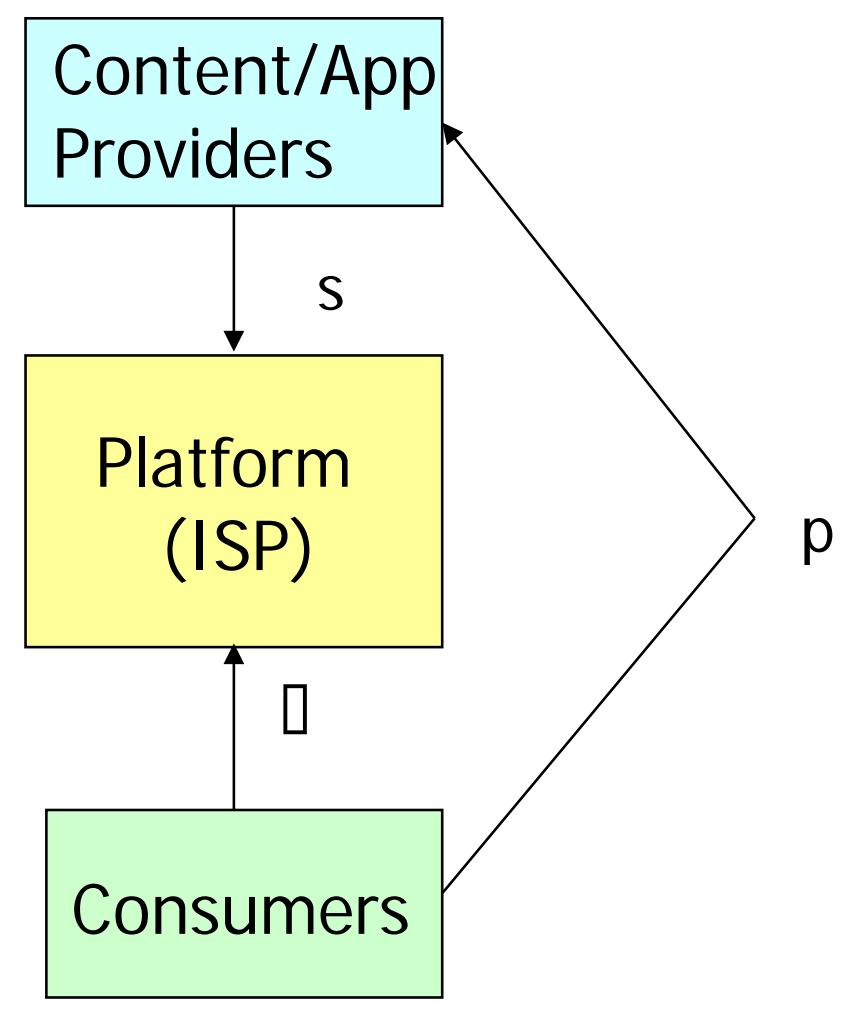

\footnotetext{
${ }^{5}$ For earlier work on two-sided pricing see Armstrong (2006), and Rochet and Tirole (2003, 2006).
} 
It is expected that on the Internet content and applications providers would like more consumers, while each consumer would like more content and applications providers. Thus, there are two feedback loops or network effects in this setup.

The general two-sided setup of Figure 2 can result in positive or negative fee $s$ assuming a positive price for $\mathrm{Q}$. For example if the platform was a computer operating system, and the content/app side was third party applications, we know that the platform typically subsidizes applications (so $s<0$ ) by embedding in the OS subroutines that are only valuable to applications' developers. If the platform was a game platform, and the content/app side was third party games, we know that the platform typically collects from software developers. If the platform is a search page on the web (or Yellow Pages in older times), we know that users are typically offered a zero price $p$, while advertisers pay a positive price $s$. If the platform is an academic journal, typically readers/users pay a positive $\mathrm{p}$ while authors do not pay a positive $\mathrm{s}$, although there are journals that are freely distributed and charge the authors publication costs (after refereeing and acceptance). If the platform is a credit card network, typically issuers pay users $(\square<0)$ and get paid by the merchants $(s>0)$. If the platform is a newspaper, typically users pay $(\square>0)$ and advertisers pay ( $(>0)$, but there are free newspapers $(\square=0)$. In the particular case we have in mind, we observe AT\&T, Verizon, Comcast, Time Warner and other residential ISPs demand a positive price $s$.

"Network neutrality" can have different definitions. Referring to pricing to the "other side” of the consumer market (that is, to content and applications providers) we may define network neutrality from the strictest to the weakest. The first, most extreme, form of network neutrality is absolute non-discrimination, that is, no quality of service variations offered for money or for free. A second, less strict form of network neutrality would allow ISPs to vary 
quality of service depending on the type of information packet or service but the ISP could not charge any fees to upstream providers for these variations. This form of network neutrality would allow the ISP to implement variations in quality of service that the consumers desire, but would still be prohibited from charging the upstream firms. All advocates of network neutrality accept that both of these definitions are consistent with network neutrality.

A third possibility for network neutrality is when tiered service is allowed but each tier is offered at the same price to all without exclusivity or identity-based discrimination. Academics and industry observers are divided on whether this is indeed network neutrality. On the one hand, within each tier, information packets are treated equally. On the other hand, across tiers, information packets are treated unequally, with prioritization given to packets in higher tiers. Thus, tiered service is generally considered a violation of net neutrality.

A fourth Internet regime could allow for identity-based discrimination, so that the same service is offered at different prices to different companies. An extreme version of this, a fifth Internet regime, would allow for full exclusivity to a particular content or application provider per industry segment. Essentially the ISP could go to an industry segment, such as to all search providers, and inform them that it would allow only one of them to be prioritized, and then auction the prioritized position. Clearly the last two regimes, identity-based discrimination and exclusivity violate network neutrality.

Because of the very considerable market power by broadband Internet access networks, there is debate on the allocative efficiency properties of complex pricing strategies that violate network neutrality as well as on their legality. Residential retail broadband Internet access customers may well have difficulty changing ISPs. Ninety-eight percent of US households are offered Internet access by at most two firms: a telephone company through Digital Subscriber 
Line ("DSL”) and a cable TV company through a cable "modem," and many households are facing a monopoly of either cable or DSL. Additionally, residential customers face switching costs, such as changing equipment and possibly the email service of the ISP. Finally residential customers are affected by contracts that bundle broadband Internet access with other services such as telecommunications and cable television.

Network neutrality has allowed firms to innovate "at the edge of the network” without seeking approval from network operator(s). The decentralization of the Internet based on net neutrality facilitated innovation resulting in big successes such as Google and Skype. Net neutrality also increased competition among the applications and services "at the edge of the network" since they did not need to own a network to provide services.

Additionally, the existence of network effects on the Internet implies that efficient prices to users on both sides (consumers and applications) should be lower than in a market without network effects. Instead we see an attempt to increase prices that will reduce network effects and innovation.

At the most fundamental level the problem of network neutrality can be analyzed as a two-sided market in either a static framework with fixed bandwidth or in a dynamic one, where the pricing regime changes the incentives to invest in bandwidth. Desirability of network neutrality can also be analyzed under the assumption of no congestion in residential Internet access or, alternatively, assuming congestion. ${ }^{6}$ Finally, the effect of network neutrality on innovation may or may not be taken into consideration.

There are many advocacy papers written on the subject, but significantly less economic

\footnotetext{
${ }^{6}$ Evidence of presence of congestion has not been presented in the FCC proceedings so far.
} 
research. Among the academic analyses, ${ }^{7}$ Economides and Tag (2012), assuming no congestion, showed that introducing a positive price to content providers is typically welfare-inferior to network neutrality. They assume a monopolist platform that charges a positive fee $\square$ to consumers. The crucial issue is the sign of the fee $\mathrm{s}$ from content and applications providers to the platform ISP. They show that the ISP would like to charge a positive s. They define as total surplus TS( $(\square, s)$ as the sum of consumer surplus, profits of the ISP and profits of content and applications providers. A regulator is given the job of choosing optimal pricing on the content side of the market. Economides and Tag (2012) shows that a total surplus maximizing regulator in a two-sided market with network effects, when constrained to marginal cost pricing on the consumer market, chooses below-cost pricing in the content market, that is, that the maximizer of $T S(c, s)$ is $s^{*}<0$, where $c$ is the marginal cost of the ISP. Essentially this is a consequence of network effects. In the presence of network effects, optimality implies pricing below cost for the end-to-end price $\square+s .{ }^{8}$ Since one side of the market was set to cost, intuitively, the other side of the market should be set at a price below cost.

Now consider a regulator setting fee $s$ to content providers expecting the platform monopolist to set its profit-maximizing price to consumers $p(s)$ taking into account $s$. Then the regulator maximizes the constrained total surplus function $\operatorname{TS}(p(s), s)$. The regulator's optimal choice is a below-cost fee $\mathrm{s}^{* *}<0$ to content providers. ${ }^{9}$ The intuition is that same as before. Network effects imply below cost end-to-end pricing $p(s)+s$. Since $p(s)$ is above cost, optimal s should be chosen below cost, here below zero. Since it is difficult to implement a negative price, the regulator can implement $s=0$ as a second best. In summary, Economides and Tag (2012)

\footnotetext{
${ }^{7}$ For a survey of academic papers, see Krämer, Wiewiorra, and Weinhardt (2013) and Lee and Wu (2009)

${ }^{8}$ In Economides and Tag (2012), $p=0$.

${ }^{9}$ This holds provided that both consumers and content providers are sufficiently differentiated. Also, even paying the below-cost fee, the platform makes positive profits.
} 
shows that there is a sharp divergence between private and public incentives, where the platform desires a positive fee from content providers while total surplus maximization implies a negative such fee which is set to zero as a second best.

There are a number of other detriments to welfare that could result from departures from network neutrality. While the ISPs have promised an enhancement of the arrival time of information packets that originate from paying content and application firms, this is not necessary to generate value for themselves. For the latter, it is sufficient to degrade the arrival time of information packets that originate from non-paying firms, while keeping the arrival timing of the paying firms the same as before the violation of network neutrality. The present plan of access providers is to create a "special lane" for the information packets of the paying firms while restricting the lane of the non-payers without expanding total capacity. By manipulating the size of the paying firms' lane, the access provider can guarantee a difference in the arrival rates of packets originating from paying and non-paying firms, even if the actual improvement in arrival time for paying firms' packets is not improved over net neutrality.

If the access providers choose to engage in "identity-based” discrimination, they can determine which one of the firms in a content or applications industry, say in search, will get priority and therefore win. This can easily be done by announcing that prioritization will be offered to only one of the search firms, for example the one that bids the highest. Thus, the determination of the winner in search and other content or applications markets will be in hands of the access providers and not determined by innovative products or services on the other side. This can create very significant distortions since the surplus of the content and applications markets is a large multiple of the combined telecom and cable TV revenue from residential Internet access. 
New firms with small capitalization (or those innovative firms that have not yet achieved significant penetration and revenues) will very likely not be the winners of a prioritization auction. This is likely lead to a calcification/freezing of industry structure and reduce innovation. Network externalities arise because a typical subscriber can reach more subscribers in a larger network. Under no network neutrality, access providers can limit the size and profitability of new firms in content and applications.

Typically access networks also provide their own content and applications, or more generally, they provide substitutes to the content and applications independent firms. For example, Netflix's customers may use Comcast to download video and films from Netflix, while Comcast sells video services delivered through cable TV. Similarly, both telecom and cable TV ISPs provide their own phone services that are also provided by independent VOIP providers such as Vonage. The ISPs may favor their own services and degrade transmission of rivals that use their pipes. This is likely to distort competition and reduce total surplus. ${ }^{10}$

Since the Internet consists of a series of interconnected networks, any one of these, and not just the final consumer access ones, can, in principle, ask content and application providers for a fee. This can result in multiple fees charged on a single transmission and lead to a significant reduction of trade on the Internet. Finally there are political and news diversity concerns if content in newspapers and websites is delayed in comparison with sites and newspapers that pay for prioritization.

The main arguments supporting abolishing network neutrality are three. First, that if the ISP collects revenue from the content providers (for example through paid prioritization), it will decrease prices to consumers. Second, that there is congestion on the local access network and

\footnotetext{
${ }^{10}$ See, for example, a recent battle between Comcast and Level 3 Communications (see, e.g., “Comcast Fee Ignites Fight over Videos on Internet,” New York Times, November 30, 2010) illustrates this point.
} 
paid prioritization can be way to alleviate it. Additionally, ISPs have claimed that the presence of congestion in the local access network automatically makes network neutrality suboptimal.

Third, that if the ISP is allowed paid prioritization, its profits will be higher and will invest more in network capacity, thereby decreasing distortions arising from network neutrality.

My assessment of these arguments is as follows. On the first issue, in many models, the ISP charging content providers leads to lower prices to users. ${ }^{11}$ This is taken into account in all models, and the welfare results take it into consideration. On the issue of congestion, it should first be noted that the ISPs have not provided evidence in their numerous submissions to the FCC that there is congestion in the local access network. Second, paid prioritization is not the optimal way to deal with congestion because the incentives of the ISP differ from the incentives of society. The way the ISPs have proposed paid prioritization, it is provider-based and not volumebased. That is, if a provider pays, its content will be prioritized compared to providers that provide substitute services. The ISPs have never proposed a system that would prioritize some and delay other information packets based on the extent of congestion, which would naturally vary with the time of the day.

Most importantly, the ISP has an incentive to create artificial scarcity over and above the natural scarcity that may be there because of congestion, and paid prioritization gives the ISPs the opportunity to do so. As seen below, Economides and Hermalin (2012) assume congestion and show that network neutrality may or may not be optimal depending on the specification of the demand.

\footnotetext{
${ }^{1111}$ Whether in fact ISPs such as AT\&T and Verizon will reduce prices under paid prioritization is highly questionable. These companies are seen by Wall Street as "utilities” that are expected to pay a high dividend. If paid prioritization were to occur, key ISPs would be under pressure to distribute the added revenue as profits rather than to reduce prices to users.
} 
Economides and Hermalin (2012) address the problem of network neutrality assuming congestion and examining for which class of additive utility functions network neutrality is optimal, and for which class prioritization is optimal. They assume homogeneous consumers, a monopolist ISP, and content and applications providers are indexed by $\theta$, with consumers considering content of higher $\theta$ to be more time-sensitive. Consumers have utility function

$$
U=y+\int_{\underline{\theta}}^{\bar{\theta}}\left(\int_{0}^{x(\theta)} m\left(\frac{x}{\alpha(\tau(\theta), \theta)}\right) d x\right) d F(\theta)
$$

where $x(\theta)$ is consumption of content of type $\theta, \tau(\theta)$ is delay of content of type $\theta, m($.$) is the$ “adjusted" marginal utility of information packets (with $m>0, m^{\prime}<0$ ), and $\alpha(\tau(\theta), \theta)$ reflects the extent that consumers care about time delay of packets of type $\theta$. High $\alpha$ is equivalent to the consumer receiving fewer packets $x$, which means higher marginal utility. ${ }^{12}$ As in Economides and Tag (2012), total surplus $W$ is defined as consumer surplus plus profits of ISPs plus profits of applications. Because consumers are homogeneous, the monopolist ISP appropriates all their consumer surplus.

Potentially, bandwidth can be divided in different lanes with each lane given a different priority. Network neutrality then corresponds to no division of the bandwidth. A key result of Economides and Hermalin (2012) is that between two alternative divisions of the total bandwidth, one is welfare-superior to the other if and only if it results in more content being carried in equilibrium than the other. Therefore the amount of content carried is a "sufficient

\footnotetext{
${ }^{12}$ Function $\alpha$ is decreasing in delay $\tau, \partial \mathrm{a} / \partial \tau<0$, and therefore $\mathrm{m}$ is decreasing in $\tau, \partial \mathrm{m} / \partial \tau<0$. Higher type $\theta$ content more time sensitive: $\partial^{2} \alpha / \partial \tau \partial \theta<0$.
} 
statistic" for welfare and how bandwidth is allocated to content among applications does not matter. Content is analogous to income, and it has the maximum positive effect on welfare when it is allocated as the consumer sees fit without restrictions. Since welfare is increasing in bandwidth used, the problem of maximizing welfare under a bandwidth allocation constraint is reduced to maximizing throughput by choosing the appropriate bandwidth allocation.

The key question is, is it possible to divide bandwidth in classes (possibly charging different prices) and increase throughput (and therefore increase total surplus)? The answer of Economides and Hermalin (2012) is that it depends on an esoteric feature of demand: on the variation with respect to content type of the elasticity of content with respect to delay. In particular, maximizing total surplus subject to bandwidth constraint shows that higher $\theta$ content should be prioritized when the partial with respect to $\theta$ of the elasticity of content sales with respect to transmission delay $\tau$ is positive. Network neutrality is optimal when the elasticity of content with respect to transmission delay does not vary in content type $\theta$. This is true for a wide class of utility functions. ${ }^{13}$ Still there are other utility functions for which prioritization is optimal.

Economides and Hermalin (2012) also find that, when network neutrality maximizes welfare, the profit-maximizing ISP will still discriminate and prioritize content. The ISP will choose prices that do not result in network neutrality. This is fundamentally because the ISP's profits do not coincide with total surplus which also includes content providers’ profits.

In a dynamic setup, when ISPs are allowed to deviate from network neutrality and invest the resulting profits in expanding bandwidth, Economides and Hermalin (2012) find that more bandwidth alleviates to some extent the static distortion, and, sometimes it may reverse it.

\footnotetext{
${ }^{13}$ In particular, network neutrality is optimal when $\alpha(\tau(\theta), \theta)=g(\tau) v(\theta)$ which means that the (lack of) preference for delay $\tau$ is "independent" of content type $\theta$.
} 
Whether the latter occurs, depends on the bandwidth expansion technology and the relative contributions to welfare of consumer surplus and profits.

In some models, for example in Choi and Kim (2010), the ISP can have higher profits if it restricts bandwidth. In that model, lower bandwidth increases the difference between the price of a good in the fast lane in comparison to the one in the slow lane. This does not occur in Economides and Hermalin (2012). Njoroge, Ozdaglar, Stier-Moses and Weintraub (2013) find that network neutrality is optimal in a "priority lanes” model (as in Economides and Hermalin (2012)) as well as in a “walled garden” model where ISPs effectively charge access fees to offnetwork CPs to deliver their content (as in Economides and Tag (2012)). ${ }^{14}$

\section{Regulatory Actions}

The FCC passed rules in December 2010 that imposed, among others, the following requirements to ISPs: ${ }^{15}$

1. Transparency: Fixed and mobile broadband providers must disclose the network management practices, performance characteristics, and terms and conditions of their broadband services. 2. No blocking: Fixed broadband providers may not block lawful content, applications, services, or non-harmful devices; mobile broadband providers may not block lawful websites, or block applications that compete with their voice or video telephony services.

3. No unreasonable discrimination: Fixed broadband providers may not unreasonably discriminate in transmitting lawful network traffic.

\footnotetext{
14 The latter result holds only when the quality of content providers' heterogeneity is large.

${ }^{15}$ The NPRM (request for comments) of the FCC (2009) stated, “Subject to reasonable network management, a provider of broadband Internet access service must treat lawful content, applications, and services in a nondiscriminatory manner. We understand the term "nondiscriminatory" to mean that a broadband Internet access service provider may not charge a content, application, or service provider for enhanced or prioritized access to the subscribers of the broadband Internet access service provider. ... We propose that this rule would not prevent a broadband Internet access service provider from charging subscribers different prices for different services.”
} 
Even though these rules were weak (since they outlawed only unreasonable discrimination rather than all paid discrimination), Verizon appealed to stop them. In January 2014, Verizon won, and the FCC rules were nullified. ${ }^{16}$ In October 2014, President Obama expressed strong support for net neutrality, "The president has made it abundantly clear that any outcome must protect net neutrality and ban paid prioritization—and has called for all necessary steps to safeguard an open Internet.”

In the rules that were nullified, the FCC had classified Internet service under "Title I" as an "information service," over which it has only "ancillary jurisdiction." The FCC could have classified Internet service as a "telecommunications service" under "Title II" which would impose strict non-discrimination. In fact, on March 12, 2015 the FCC reclassified the Internet as a telecommunications service falling under Title II. ${ }^{17}$ This imposes strict non-discrimination and bans paid prioritization. Essentially this rule adopts strict network neutrality. Industry group USTelecom (that includes AT\&T and Verizon) sued the FCC on the validity of the rules on March 23, 2015. It is very early to judge the probability of success of this challenge.

\section{Concluding Remarks}

We identified salient features of the Internet and focused on the issue of network neutrality. Local broadband access residential ISPs possess market power and have proposed abolishing the present regime of no paid prioritization that has been called "network neutrality."

\footnotetext{
${ }^{16}$ The case was Verizon v. F.C.C., D.C. Cir. No.11-1355 (Jan. 14, 2014). The essence of the decision is "[E]ven though the $[\mathrm{FCC}]$ has general authority to regulate in this arena, it may not impose requirements that contravene express statutory mandates. Given that the Commission has chosen to classify broadband providers in a manner that exempts them from treatment as common carriers, the Communications Act expressly prohibits the Commission from nonetheless regulating them as such. Because the Commission has failed to establish that the antidiscrimination and anti-blocking rules do not impose per se common carrier obligations, we vacate those portions of the Open Internet Order.”

${ }^{17}$ Federal Communications Commission, Report and Order 14-28, March 12, 2015/.
} 
We discuss how abolition of network neutrality and introduction of paid prioritization can result in significant reduction in the surplus created in the Internet ecosystem. In particular, we show how abolition of network neutrality can create an allocative distortion and reduce total surplus. However, profits accrued to the ISP from a violation of network neutrality, if used to expand bandwidth, can alleviate the allocative distortion caused by violating network neutrality. Additionally we describe how abolition of network neutrality could significantly reduce innovation at the edge of the network.

\section{5. $\quad$ References}

Armstrong, Mark (2006), "Competition in two-sided markets," RAND Journal of Economics, vol. 37, pp. 668-691.

Bradner, Scott (1999), The Internet Standards Process, revision 3, Network Working Group, at ftp://ftp.isi.edu/in-notes/rfc2026.txt .

Cheng, H.K., Bandyopadhyay, S., and Guo, H. (2011), "The Debate on Net Neutrality: A Policy Perspective,” Information Systems Research, vol. 22, pp. 60-82.

Choi, J.P. and Kim, B.C. (2010), “Net Neutrality and Investment Incentives,” RAND Journal of Economics, vol. 41, pp. 446-471.

Economides, Nicholas (1996), “The Economics of Networks,” International Journal of Industrial Organization, vol. 14, no. 2, pp. 675-699.

Economides, Nicholas and Benjamin Hermalin “The Economics of Network Neutrality,” (with Benjamin Hermalin), RAND Journal of Economics, vol. 43, no. 4, Winter 2012, pp. 602629, at http://www.stern.nyu.edu/networks/EconomidesHermalin_Economics_of_Network_Neutrality.pdf. 
Economides, Nicholas and with Joacim Tag (2012), "Network Neutrality on the Internet: A Twosided Market Analysis,” Information Economics and Policy, vol. 24, pp. 91-104, at http://www.stern.nyu.edu/networks/Economides_Tag_Net_Neutrality.pdf .

Federal Communications Commission, Report and Order 10-201, Washington, DC, 2010.

Federal Communications Commission, Report and Order 14-28, Washington, DC, March12, 2015.

Hermalin, Benjamin and Michael Katz (2007), “The Economics of Product-Line Restrictions with an Application to the Network Neutrality Debate.” Information Economics and Policy, vol. 19, pp. 215-248.

Kahn, Robert E. and Vinton G. Cerf (1999), "What Is The Internet (And What Makes It Work)," at http://www.wcom.com/about the_company/cerfs_up/internet_history/whatIs.phtml.

Katz, Michael and Carl Shapiro (1985), “Network Externalities, Competition and Compatibility,” American Economic Review, vol. 75, no. 3, pp. 424-440.

Krämer, Jan and Wiewiorra, Lukas (2010), “Network Neutrality and Congestion-Sensitive Content Providers: Implications for Service Innovation, Broadband Investment and Regulation.” NET Institute Working Paper 10-09.

Krämer, Jan, Lukas Wiewiorra, and Christof Weinhardt (2013), “Net neutrality: A Progress Report,” Telecommunications Policy vol. 37, no. 9, pp. 794-813.

Liebowitz, Stanley J. and Stephen E. Margolis, “Network Externality: An Uncommon Tragedy,” The Journal of Economic Perspectives (Spring 1994), pp. 133-150.

Lee, Robin S. and Tim Wu, "Subsidizing Creativity through Network Design: Zero-Pricing and Net Neutrality,” Journal of Economic Perspectives, vol. 23 (3), Summer 2009, pp. 61-76. 
Njoroge, Paul, Asuman Ozdaglar, Nicolás E. Stier-Moses and Gabriel Y. Weintraub (2014), “Investment in Two-Sided Markets and the Net Neutrality Debate,” Review of Network Economics, vol. 12, no. 4, pp. 355-402.

Rochet, J., Tirole, J. (2003), “Platform competition in two-sided markets.” Journal of the European Economic Association, vol. 1, pp. 990-1029.

Rochet, J., Tirole, J. (2006), “Two-sided markets: a Progress Report,” RAND Journal of Economics, vol. 37, pp. 645 - 667. 